\title{
The challenges of instructors' and students' attitudes in digital transformation: A case study of Saudi Universities
}

\author{
Abdulaziz Alhubaishy $^{1}$ (D) Abdulmajeed Aljuhani ${ }^{2}$
}

Received: 2 December 2020 / Accepted: 4 March 2021 / Published online: 16 March 2021

(c) The Author(s), under exclusive licence to Springer Science+Business Media, LLC, part of Springer Nature 2021

\begin{abstract}
Digital Transformation (DT) has become the core motivator for almost all organizations worldwide. In order to cope up with the new demands, Higher Education Institutions (HEIs) are also giving due consideration to digitizing their services, including pedagogical services. Many challenges are being faced during the successful adoption of DT strategies and plans. One of the main obstacles is the set of challenges related to the stakeholders in HEIs; more precisely, instructors and students. This paper extracts, synthesizes, categorizes, and prioritizes the challenges hindering the success of DT in Saudi universities. Firstly, the paper extracts the main challenges faced by instructors and students, and then constructs a model of the challenges based on the tripartite classification of attitude. The paper adopts a Multi-Criteria Decision Making (MCDM) Method, called the Analytic Network Process (ANP), for the purpose of gathering instructors' and students' evaluations and prioritizing their challenges accordingly. A total of 25 instructors and students were recruited from various HEIs in Saudi Arabia to evaluate the model. The results show that learning performance, lack of access to resources, and fear of change are the most significant factors hindering students towards successful adoption of DT. On the other hand, fear of change followed by lack of experience and privacy concerns are the most significant factors hindering instructors towards successful adoption of DT. The research is intended to enlighten decision-makers in Saudi HEIs to consider non-technical challenges while planning for digitizing HEIs services.
\end{abstract}

Keywords Digital transformation - Digitalization - DT challenges · DT strategies · Saudi Universities

Abdulaziz Alhubaishy

a.alhubaishy@seu.edu.sa

Abdulmajeed Aljuhani

abaljuhani@taibahu.edu.sa

1 College of Computing and Informatics, Saudi Electronic University, Riyadh 11673 ,

Saudi Arabia

2 College of Computer Science and Engineering, Taibah University, Medina, Saudi Arabia 


\section{Introduction}

Presently, globalization and rapid transformation to digitalization are some of the motivators for organizations to re-design their strategies and remain competitive (Westerman et al., 2011). Organizations can maintain customer satisfaction and facilitate survival in the marketplace by continuously meeting novel demands (Bharadwaj, 2000). Higher Education Institutions (HEIs) also continuously face new demands by considering changes to pedagogical approaches and their underlying processes. This transformation is certainly affecting and affected by both instructors and students. Human factors are considered one of the pillars of the success or failure of a digital transformation strategy. Thus, Reis et al. (2018) have categorized digital transformation into three aspects; 1) Technological: use of new technology, 2) Organizational: creating or changing business models, and 3) Social: influencing human life.

The literature has enriched the field with challenges hindering the successful adoption of digital transformation in organizations; especially, human challenges (Bozanta \& Mardikyan, 2017). A few studies have identified the challenges encountered by digital transformation within HEIs. For example, Al-Ohali et al. (2019) identified lack of resources and support, along with the lack of related skills by students and teachers, as the main challenges hindering the adoption of technology in classrooms.

Saudi Arabia is a developed country where many of its public and private universities have been established within the last two decades. Saudi Arabia has been implementing the National Transformation Program (NTP) within a national vision, called Saudi Vision 2030. One of the main objectives of the NTP is to establish and accelerate the implementation of "digital infrastructure projects" (Saudi Vision 2030, 2018). Saudi universities share this objective by designing and adopting DT plans and strategies. However, differences, such as culture, urge researchers to research barriers to adoption of plans and strategies within Saudi universities.

This paper extracts, synthesizes, categorizes, and examines the challenges that influence or have influenced instructors or students; which effectually lead to hindering the success of digital transformation in Saudi universities. Firstly, most of the challenges related to digital transformation and human interactions and collaboration are extracted from the literature. They are synthesized and categorized within the HEIs based on the tripartite classification of human attitude. Finally, the level of importance of each challenge within Saudi universities are examined by conducting a case study to collect instructors' and students' evaluations of these challenges and prioritizing them using a Multi-Criteria Decision Making Method called the Analytic Network Process (ANP). The following steps summarize the methodology to achieve the objective of this research.

1) Identify the influential factors related to instructors and students hindering the successful application of DT strategies.

2) Synthesize the extracted factors within the higher education environment. 
3) Group factors and create a model based on the tripartite classification of human attitude.

4) Conduct a case study to evaluate the extracted factors and prioritize them based on adopting the ANP.

5) Provide instructors, students, and other stakeholders with recommendations based on the analysis of the case study results to overcome attitudinal challenges while planning and adopting DT strategies.

\section{Literature review}

Reis et al. (2018) categorized the meaning of digital transformation into three categories: technological, organizational, and social. The technological point of view pertains to using new technology, such as social media and embedded devices (Fitzgerald et al., 2014). The organizational point of view deals with the adoption of new business models or changes to current processes (Stolterman \& Fors, 2004). The social point of view concerns the influence digital transformation has on human life (Solis et al., 2014).

Digital transformation faces challenges related to the two foremost influencers to this transformation: technology and people. Technology plays its role by creating a new era for companies to move their services toward digitalization and adapt their business models accordingly. People, on the other hand, increase the adoption of the transformation as a strategy. However, the existing literature has highlighted different challenges related to both players facing successful adoption of digital transformation.

Heavin and Power (2018) highlighted, from the existing literature, seven main challenges managers face while adopting digital transformation. The challenges include priority of increasing operational efficiency vs. customer need, focusing on a group of customers vs. individuals as a result of analyzing aggregated data, providing more resources to IT and non-IT employees, the amount of data to store vs. the cost of storage, task automation, security and accessibility of data and their importance based on different domains, and understanding customers vs. privacy of their data and behaviors (Tiersky, 2017; Panetta, 2016; Newman, 2017; Filkinset al., 2016; Bharadwaj et al., 2013). Heavin and Power (2018) proposed a decision support guidance to enable managers to successfully consider these challenges based on types of tasks related to each decision level: strategic, tactical, and operational decisions.

Durão et al. (2019) have studied the implementation of digital transformation by Portuguese organizations. The authors found leadership and organizational culture are playing an important role in implementation of digital transformation. Within leadership, managerial resistance has been found to be an obstacle to implementing digital transformation, while lack of skills is an obstacle found in organizational cultures.

Yucel (2018) has highlighted different challenges faced by organizations and their associated risks while digitizing their businesses; including the cost and complexity of digital transformation and their strategies, distraction from business, undesirable 
results influencing profit, the security of an organization's data, and privacy of its customer data. The author has categorized the risks based on different domains such as risks related to technology, business challenges, adopted strategy, and support and sponsorship.

To some extent, many of the aforementioned obstacles apply to Higher Education Institutes (HEIs). Limani et al. (2019) have highlighted the decision-making process and planning are significantly affected by the institute's flexibility, which plays an important role in the success of implementing digital transformation. The authors found private HEIs have better financial flexibility, hence a better tendency to adopt digital transformation. The authors have continued by highlighting recommendations for HEIs while adopting a strategic plan for digital transformation. These recommendations include determining the necessary technology and its impact on academic and non-academic processes; involving all stakeholders during the preparation of the strategic plan, consideration of security issues, assuring the applicability of strategy, consideration of the cost of transformation, and supporting students while adopting new technologies.

Digital transformation has been adopted in several educational organizations to facilitate the learning process regarding its ability to overcome different challenges, such as time and capacity in traditional learning. Bozanta and Mardikyan (2017) conducted a study to investigate the social media impacts on collaborative learning. Based on a questionnaire distributed among Turkish universities, the findings revealed the perceived ease of use is a foreteller for perceived usefulness affecting social media utilized by students for educational purposes. According to the authors, interaction among students, the interaction between instructors and students, and student engagement has been enhanced by use of social media. Results allude to peer interaction and engagement in the course, which have an important constructive influence on collaborative learning. These findings may be beneficial for students and instructors in their capacity to benefit from the use of social media in the e-learning environment.

Rashid and Asghar (2016) conducted a study to understand the association between several factors such as the use of technology, academic performance, self-directed learning, and student engagement. The authors collected data from 761 undergraduate students. The findings of their study exhibited that technology use has a positive effect on self-directed learning and student engagement. However, the study showed the use of technology had no influence on student academic performance.

On the other hand, several studies showed the use of technology had a positive impact on student performance. For example, Fonseca et al. (2014) argued students had a high level of engagement with the introduced content, resulting in enhanced overall achievement. The authors emphasized that student motivation correlates strongly with technology. In addition, their study showed the use of technology has a significant impact on student academic achievement.

Research points out that motivated students have more opportunities for achieving higher learning performance levels, contributing to enhanced student knowledge through peer interaction, interaction with their instructors, and the study of course materials (Blasco-Arcas et al., 2013; Pérez-López et al., 2020). 
Student engagement is classified as a top strategic priority in higher educational institutions (Cassidy et al., 2019). According to Trowler (2010), several reasons motivate educational institutions to maintain student engagement. These reasons include enhancing student performance regarding the increase in active collaboration in the learning process, enhancing retention rates, enhancing weak student skills, increasing the institution's reputation, and gaining more financial support for the institution.

Several barriers accompany this use despite the value of educational use of technology. For example, Joseph (2012) classified the barriers to educational technology into various categories, such as student barriers; which includes special needs of the students, and increasing printing costs. The educators' categorical barriers include the system responding against instructors' inputs, the effect of cultural implications on student attendance, security issues, and academic plagiarism.

Proposing MCDM methods on DT is still limited; however, few studies investigate the adoption of MCDM for technological selection in industrial fields. In this context, Erbay and Yıldırım (2018) integrated the analytic hierarchy process with quality functional deployment in order to rank Industry 4.0 DT technologies and methods for choosing technology in the manufacturing industry. The authors adopt the MCDM to evaluate the adoption of DT in industrial environments based on three categories: benefits, tools, and challenges. The authors identified several benefits ranked based on the AHP approach, such as minimizing workforce requirements, enhancing the quality of work, maximizing process efficiency. In addition, challenges like security concerns, budget shortage, lack of experienced workers, and tools such as, augmented/virtual reality, radio frequency identification (RFID), and $3 \mathrm{D}$ printing, are identified in the hierarchy decision model in order to prioritize these tools, benefits, and challenges. Their results showed maximizing process efficiency was ranked at the top position among all benefits. Furthermore, data analytics and lack of experienced staff were ranked in the top position with respect to tools and categorical challenges, respectively.

\section{Model of human attitude factors affecting the adoption of digital transformation in HEls}

Behavioral engagement can be exhibited in several dimensions, such as being active, being present, completing schoolwork, and other features that may involve noticeable behaviors imperative to academic achievement as stated by Fredricks et al. (2004). Emotional engagement incorporates students' social connections with different learners within an institution and the emotions they have about the learning experience, such as fatigue, disappointment, and interest (Henrie et al., 2015). Furthermore, according to Fredricks et al. (2004), the engaged exertion facilitates students when comprehending what is being instructed. This involves self-guidelines and metacognitive behavior which is considered a cognitive engagement. Figure 1 shows the tripartite classification of attitude containing the three main dimensions.

In the cognitive dimension, the use of new technologies enhances the student experience and has a positive impact on collaborative learning (Pérez-López et al., 


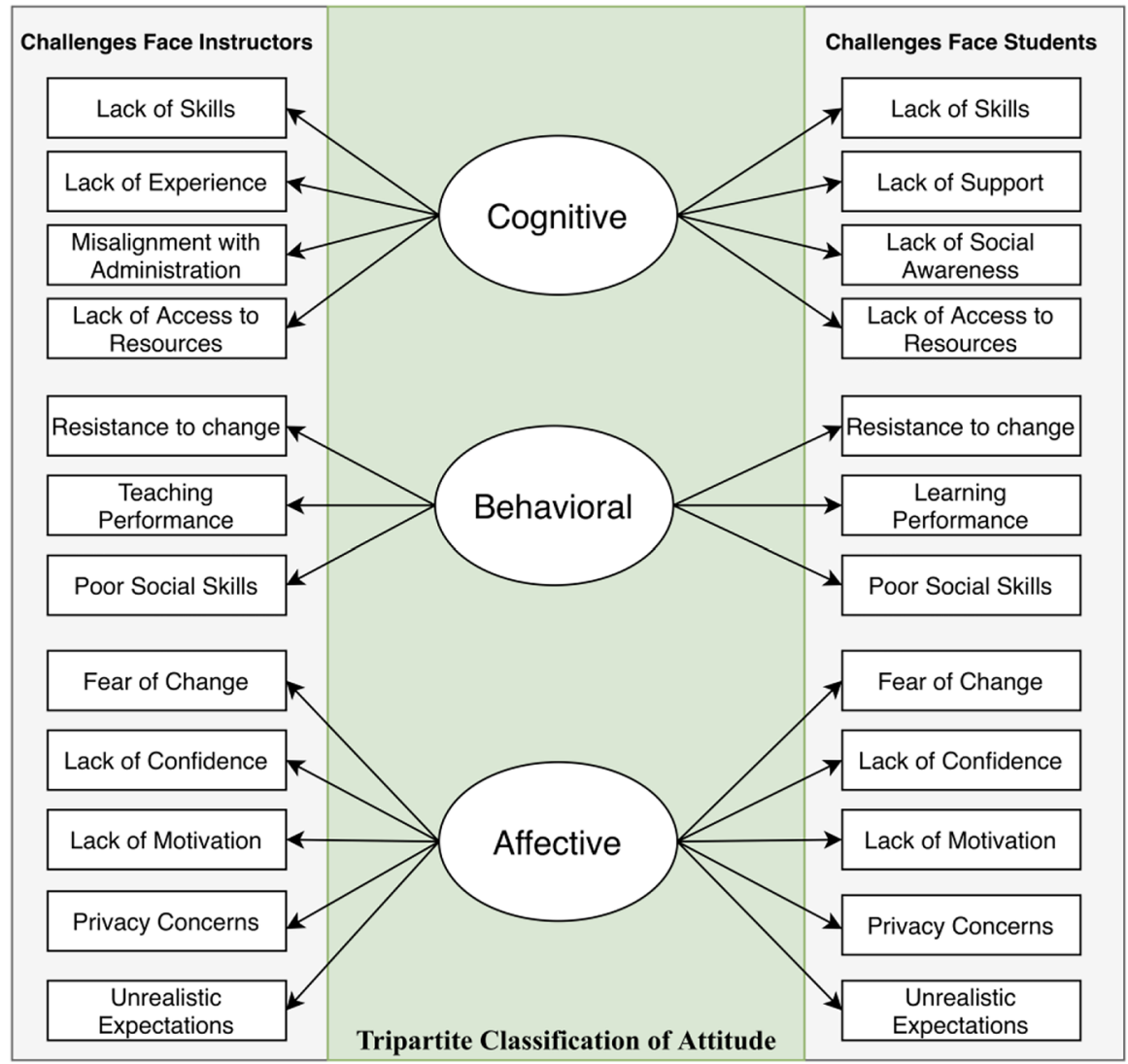

Fig. 1 Attitudinal challenges of adopting digital transformation in educational environments

2020). Several examples of technological use can be provided from this perspective, such as social media, which is commonly used to enhance cognitive engagement among students and between students and their instructors. According to Rasiah (2014), the social network sites have valuable impacts on collaborative learning, such as creating a positive educational environment leading to added student engagement and improved learning experiences. Therefore, in this paper, the following challenges are categorized into cognitive dimension: 1) "Lack of access to resources", 2) Lack of student Support while adopting new technology, 3) Lack of social awareness, 4) "Misalignment between teachers and administrators creates difficulty for teachers", 5) Lack of experience, and 6) "Poor computer skills" (Joseph, 2012).

In the behavioral dimension, student learning has been enhanced due to the adoption of new educational technologies. For example, Al-Rahmi et al. (2018) showed adopting tools, such as social network sites, enhances student involvement and promotes more sharing opportunities. However, to reach valuable engagement and avoid wasting time, students should be encouraged by instructors through beneficial 


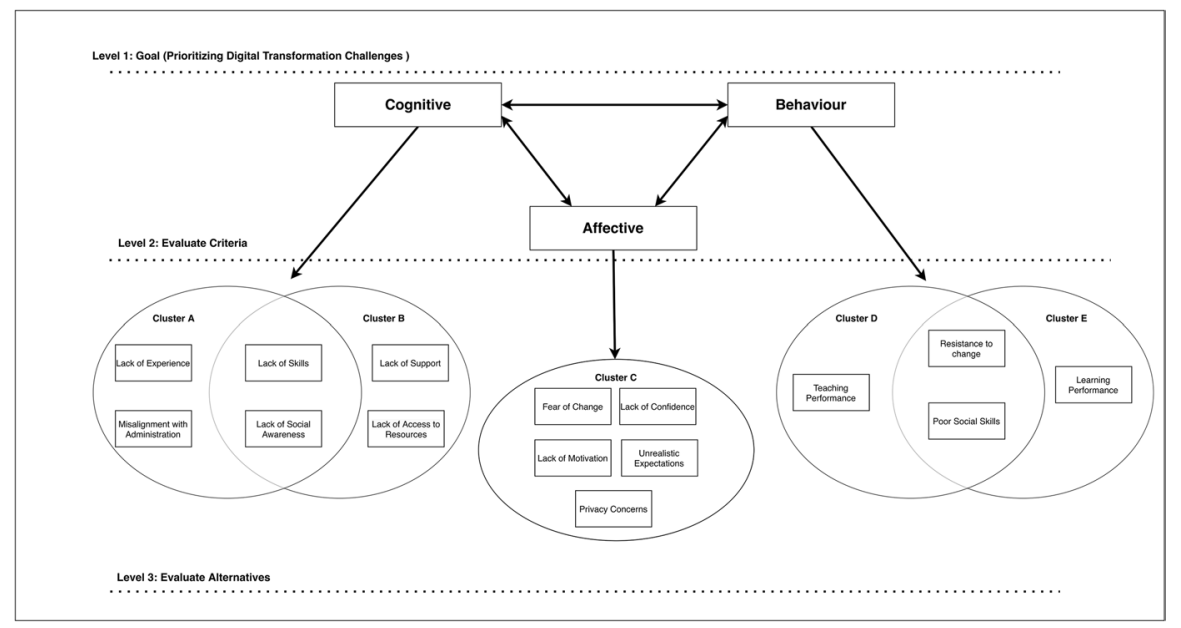

Fig. 2 Clusters of challenges facing instructors and students

activities that ensure student enjoyment and satisfaction to enhance student learning performance. In this context, the following challenges are classified in the behavioral dimension: 1) Resistance to change, 2) Teaching performance, 3) Learning performance, and 4) Poor social skills.

According to Pérez-López et al. (2020), the encouragement of enjoyment in educational activities produces learning engagement in the affective dimension. Students who enjoy their academic activities, have the opportunity to enhance their learning performance regarding the relationship between enjoyment, positive influences, positive outcomes, and educational achievements. On the other hand, poor academic performance and disengagement might be a result of the lack of student enjoyment. The adoption of educational technologies achieves motivation and excitement that students feel are key factors in engagement, leading to achievement of students' satisfaction. In this paper, the following challenges are classified into the affective category: 1) Lack of confidence, 2) Fear of change, 3) Lack of motivation, 4) Unrealistic expectations, and 5) Privacy concerns.

Figure 2 depicts all challenges in five clusters; where clusters A and D contain instructor challenges, clusters B and E contain student challenges, and cluster C contains student and instructor challenges.

\section{The analytic network process}

According to Saaty (1990), the Analytic Network Process (ANP) is the generalization of the Analytic Hierarchy Process (AHP). The essential structure is an impact network of clusters and nodes contained within the clusters. Priorities are set up, as they are in the AHP, utilizing pairwise comparisons and individual judgment. Numerous decision problems cannot be organized hierarchically in light of the fact they include the connection and dependence of higher-level components in a 
hierarchy of lower level components. The significance of the criteria does not exclusively decide the significance of the alternatives as in a hierarchy, yet the significance of the alternatives themselves decide the significance of the criteria. Feedback empowers us to consider the future and the present to figure out what we need to do to achieve a coveted future.

The Analytic Network Process (ANP) is a multi-criteria hypothesis of measurement used to infer relative priority scales of outright numbers from singular judgments (or from genuine measurement standardized to a relative frame) that have a place within a fundamental scale of absolute numbers. These judgments illustrate the relative impact of one of two components over the other in a pairwise comparison process on a third component in the network, regarding a control node. Through its super matrix, the ANP incorporates the result of dependence and the feedback inside and between the elements of the clusters. The Analytic Hierarchy Process (AHP), with its independence assumptions on upper levels from lower levels and the independence of the components at a level is an exceptional instance of the ANP. The ANP is a basic approach for articulating our comprehension of a decision problem. One needs to conquer the restriction of direct hierarchical structures and their numerical outcomes. More explanation about the ANP and its steps can be found in Saaty (1990).

The reason for selecting this approach comes from several issues regarding the benefits that the ANP method has over similar MCDM approaches. First of all, the ANP is considered simple and less complex in comparison to other MCDM approaches, which helps improve the board comprehension and straightforwardness of the modelling method. In addition, the ANP allows decision makers to merge quantitative and qualitative factors into a decision. Another benefit of the ANP method is its ability to be integrated with different decision methods such as fuzzy ANP and goal programming. Furthermore, each participant has his/her own judgments, which ensure that everyone's voice is heard during the decision process. In ANP, evaluation elicitations are accomplished utilizing a break down methodology, which leads to reduced errors in decision making as exhibited in experimental investigations (Taslicali \& Ercan, 2006).

According to Saaty (1990), the ANP is a non-linear approach, which allows decision makers to structure a decision problem in a network that allows decision makers to consider the interdependence among the network elements. This structure makes the ANP a powerful MCDM method which gives the decision makers an opportunity to compare high level elements with respect to low level criteria, which is known as feedback in the ANP process. Moreover, the ANP structure reduces the order change problem in an item's priorities, in case of addition or removal of items. This aligns the ANP closer to reality and represents real world problems in order to ensure appropriate solutions for these problems.

In this paper, the ANP structure helps capture the important dimensions and challenges affecting the tripartite classification of the attitude model and the findings of adopting the ANP show the ranking of the challenges based on their significance. Another valuable side of the ANP method is its ability to involve a beneficial debate and improve team communication. Using ANP, conflicting opinions are clarified among decision makers based on a scientific approach. 


\section{Case study}

A case study is designed by exposing the factors affecting the level of influence of extracted challenges influencing the DT in Saudi universities to a number of participants. The ultimate goal is to prioritize the challenges based on the different players; i.e. instructors and students. A snowball sampling strategy was used, beginning with a few instructors and students and asking them to recruit other instructors and students in any Saudi universities. Instructors and students were given the challenges they face during the DT. A total of 25 instructors and students participated in the study. Due to conditions caused by the Corona Virus (COVID-19), all communication took place online; where the evaluation documents, such as evaluation matrices, were sent and explained through electronic mail and online communication.

The demographic variables of the instructor participants show a moderate level of teaching experience, between 2 to 8 years. Regarding gender, two-thirds of instructors are male, and one-third are female. All recruited instructors belong to Saudi public universities, while some of them administer DT at their universities. Regarding student participants, male students constituted around $60 \%$, and female students constituted around $40 \%$ of total responses. All student participants are from public universities with different majors and levels.

The ANP methodology was followed for the instructors by creating a total of four matrices to evaluate all challenges in the model. Before starting the evaluation process, the instructors were introduced to the definition for each of the three categories of attitude, i.e. cognitive, behavioral, and affective, in order to ensure that instructors fully understood them. The first matrix enables the participants to evaluate three categories. Participants are provided Saaty's scale ranging from 1 to 9, where 1 denotes equal importance between two challenges/factors and 9 denotes the extreme importance of a challenge/factor over the other (Saaty, 1990). The other three matrices acquire instructors' evaluations for each cluster of challenges; i.e. a separate matrix for evaluating challenges of clusters A, C, and D, respectively.

The same procedure was followed for the students by creating a matrix for acquiring the evaluation of the three categories along with three matrices for acquiring the students' evaluations of each challenge cluster; i.e. a separate matrix for evaluating challenges of cluster B, C, and E, respectively.

\section{Results}

The Super Decisions software is used to prioritize the DT challenges based on the ANP (Saaty, 2003) in order to aggregate all received responses as well as to calculate the weight for each item in the model.

The analysis of student evaluations shows cognition is ranked as the most important dimension among others followed by the behavioral and affective dimensions, as shown in Table 1. 
Table 1 Ranking students' attitudes clusters

Table 2 Ranking of students' cognitive challenges

Table 3 Ranking students' behavioral challenges

Table 4 Ranking students' affective challenges

\begin{tabular}{lll}
\hline Rank & Human Attitude Dimension & Weight \\
\hline 1 & Cognitive & $78.37 \%$ \\
2 & Behavioral & $13.49 \%$ \\
3 & Affective & $8.13 \%$ \\
\hline
\end{tabular}

\begin{tabular}{lll}
\hline Rank & Cognitive Challenge & Weight \\
\hline 1 & Lack of access to resources & $47.67 \%$ \\
2 & Lack of skills & $24.45 \%$ \\
3 & Lack of support & $16.03 \%$ \\
4 & Lack of social awareness & $11.74 \%$ \\
\hline
\end{tabular}

\begin{tabular}{lll}
\hline Rank & Behavioral Challenge & Weight \\
\hline 1 & Learning performance & $66.12 \%$ \\
2 & Resistance to change & $27.17 \%$ \\
3 & Poor social skills & $6.70 \%$ \\
\hline
\end{tabular}

\begin{tabular}{lll}
\hline Rank & Affective Challenge & Weight \\
\hline 1 & Fear of change & $43.51 \%$ \\
2 & Lack of motivation & $24.12 \%$ \\
3 & Privacy concerns & $18.39 \%$ \\
4 & Unrealistic expectations & $10.34 \%$ \\
5 & Lack of confidence & $3.62 \%$ \\
\hline
\end{tabular}

As mentioned, each dimension includes several challenges, which are ranked by the participants concerning their main dimension. Concerning the cognitive dimension, the analysis shows students ranked the lack of access to resources as the foremost challenge, followed by lack of skills, lack of support, and lack of social awareness, as exhibited in Table 2.

Within the behavioral dimension, students ranked the learning performance challenge as the foremost challenge, followed by resistance to change and poor social skills, as shown in Table 3.

Within the third dimension, students evaluated the challenges with respect to the affective dimension, where the results show that fear of change is evaluated as the foremost challenge, followed by lack of motivation, privacy concerns, unrealistic expectations, and lack of confidence, as shown in Table 4. 
An overall analysis of all students' evaluations shows that learning performance from the behavioral dimension is ranked as the most important challenge followed by the lack of access to resources from the cognitive dimension and fear of change from the affective dimension. The three challenges constituted $52.61 \%$ of the influence on the success of adopting DT. Table 5 shows the ranking and weight of all challenges from the three dimensions.

Similarly, the instructors evaluated the three dimensions to explore which dimension had more influence. The analysis shows the behavioral dimension was ranked as the most significant dimension, followed by the cognitive and affective dimensions, as shown in Table 6.

In terms of prioritizing challenges of each dimension, analysis of the instructors' evaluations prioritized the resistance to change challenge as the foremost challenge, followed by teaching performance, and poor social skills challenges, as shown in Table 7.

Within the cognitive dimension, the lack of experience was ranked as the most important challenge by the participants. Furthermore, misalignment with the

Table 5 Overall ranking of students' challenges

\begin{tabular}{lll}
\hline Rank & Student's Attitude Challenge & Weight \\
\hline 1 & Learning performance & $22.03 \%$ \\
2 & Lack of access to resources & $16.08 \%$ \\
3 & Fear of change & $14.50 \%$ \\
4 & Resistance to change & $9.05 \%$ \\
5 & Lack of skills & $8.16 \%$ \\
6 & Lack of motivation & $8.04 \%$ \\
7 & Privacy concerns & $6.13 \%$ \\
8 & Lack of support & $4.92 \%$ \\
9 & Lack of social awareness & $4.16 \%$ \\
10 & Unrealistic expectations & $3.44 \%$ \\
11 & Poor social skills & $2.23 \%$ \\
12 & Lack of confidence & $1.20 \%$ \\
\hline
\end{tabular}

Table 6 Ranking instructors' attitudes clusters

\begin{tabular}{lll}
\hline Rank & Human Attitude Dimension & Weight \\
\hline 1 & Behavioral & $49.33 \%$ \\
2 & Cognitive & $31.08 \%$ \\
3 & Affective & $19.58 \%$ \\
\hline
\end{tabular}

Table 7 Ranking of instructors' behavioral challenges

\begin{tabular}{lll}
\hline Rank & Behavioral Challenge & Weight \\
\hline 1 & Resistance to change & $58.51 \%$ \\
2 & Teaching performance & $30.90 \%$ \\
3 & Poor social skills & $10.94 \%$ \\
\hline
\end{tabular}


Table 8 Ranking of instructors' cognitive challenges

\begin{tabular}{lll}
\hline Rank & Cognitive Challenge & Weight \\
\hline 1 & Lack of experience & $56.56 \%$ \\
2 & Misalignment with administration & $22.08 \%$ \\
3 & Lack of skills & $15.35 \%$ \\
4 & Lack of social awareness & $6.00 \%$ \\
\hline
\end{tabular}

administration challenge was ranked second, followed by lack of skills, and lack of social awareness, as shown in Table 8 .

Within the affective dimension, the privacy concerns challenge was ranked as the first, followed by unrealistic expectations, fear of change, lack of motivation, and lack of confidence, as exhibited in Table 9. Concerning all three dimensions, an analysis of all the instructors' evaluations showed resistance to change from the behavioral dimension is ranked as the most important challenge, followed by the lack of experience from the cognitive dimension, and privacy concerns from the affective dimension. These three challenges constituted $54.33 \%$ of the influence on the success of adopting DT. Table 10 shows the ranking and weight of all challenges from the three dimensions.

Table 9 Ranking of instructors' affective challenges

\begin{tabular}{lll}
\hline Rank & Affective Challenge & Weight \\
\hline 1 & Privacy concerns & $48.30 \%$ \\
2 & Unrealistic expectations & $28.95 \%$ \\
3 & Fear of change & $11.78 \%$ \\
4 & Lack of motivation & $6.69 \%$ \\
5 & Lack of confidence & $4.26 \%$ \\
\hline
\end{tabular}

Table 10 Overall ranking of instructors' challenges

\begin{tabular}{lll}
\hline Rank & Instructor's Attitude Challenge & Weight \\
\hline 1 & Resistance to change & $19.38 \%$ \\
2 & Lack of experience & $18.85 \%$ \\
3 & Privacy concerns & $16.10 \%$ \\
4 & Teaching performance & $10.29 \%$ \\
5 & Unrealistic expectations & $9.65 \%$ \\
6 & Misalignment with administration & $7.35 \%$ \\
7 & Lack of skills & $5.11 \%$ \\
8 & Fear of change & $3.92 \%$ \\
9 & Poor social skills & $3.64 \%$ \\
10 & Lack of motivation & $2.23 \%$ \\
11 & Lack of social awareness & $2.00 \%$ \\
12 & Lack of confidence & $1.42 \%$ \\
\hline
\end{tabular}




\subsection{Observations:}

- The learning performance challenge was ranked at the topmost position among all challenges from the student perspective, while teaching performance was ranked at the fourth position from the instructor point of view.

- Resistance to change is ranked at the topmost position among all challenges based on the instructors' evaluations. However, the students ranked resistance to change at the fourth position among all challenges.

- Both instructors and students ranked lack of confidence challenge at the last position among all challenges.

- Concerning each cluster individually, both instructors and students ranked lack of social awareness challenge at the last position in the cognitive cluster.

- Both instructors and students ranked poor social skills at the last position for behavioral criterion.

\section{Recommendations}

Our findings contribute to helping all stakeholders in Saudi HEIs, such as students, instructors, and decision-makers. Overall, students should understand that their learning performance plays the most important role in their acceptance of digital services in their institutes. A high level of learning performance influences the success of HEI plans to digitalize more services, including digitizing pedagogical methods. Access to resources is also an important factor that is primarily related to student learning performance. Therefore, DT success necessitates making resources available to a wider pool of students to ensure overcoming the lack of resource challenges. Resistance and fear of change affects students, where their age helps decrease this influence. Most current university students belong to Generation Z; the age of digital technology and social media.

Resistance to change by instructors is the most important factor that influences DT. The ability of instructors to adapt to new technology and services will help in the success of DT. Unlike students, the age of instructors plays an important role in their resistance to accept new technology and services. Instructors need to address this issue and overcome the challenge by adapting themselves to new technologies and services frequently. Experience also plays an important role, where expert instructors are more aware of the benefits DT in HEIs.

Decision-makers in HEIs can consider the non-technical factors that have an impact on adopting DT. Decision-makers should consider these factors with the DT plan and strategy. Firstly, decision-makers should give due consideration to the differences between different influences of challenges affecting students and instructors. Working on providing digital services should not negatively influence or hinder student learning performance. For example, deciding on an online learning system with an unsuitable User Interface (UI) can influence student learning performance, hence the acceptance of the learning system itself. Furthermore, decision-makers should assure the availability of required resources to reach the institute's digital products and services. This includes defining required resources, highlighting the 
availability of resources to the institute students, and geographical distance to reach resources, among others. These factors should be included while digitizing HEI products and services.

Decision-makers should give due consideration to different instructors' factors while planning DT. Level of experience and age of instructors are among the factors, where decision-makers should plan to increase the number of expert instructors and decrease the level of resistance to change by instructors. Furthermore, even though the privacy issue is the main challenge in DT, it appears a hinderance to the success of DT from the instructors' perspective. Decision-makers should plan to ensure the privacy of both instructors and students along with exposing the strategies adopted to assure instructors' privacy of their data.

\section{Conclusion}

The findings of this paper contribute to enlightening the consideration of nontechnical factors impacting the adoption of DT in Saudi HEIs. We studied several challenges that are encountered by HEIs in Saudi universities, and categorized and prioritized these challenges from the perspectives of both instructors and students. The model was built based on the tripartite classification of attitude containing three main dimensions, which are cognitive, behavioral, and affective. Each dimension includes several challenges regarding either instructors or students. The ANP approach was adopted as a decision tool to prioritize these challenges as well as to determine the most significant challenges hindering the success of DT in Saudi HEIs. Learning performance, lack of access to resources, and fear of change are among the most important challenges hindering student engagement with digital products and services in HEIs. On the other hand, resistance to change, lack of experience, and privacy are among challenges hindering instructor engagement in digital products and services of HEIs. In addition to different types of challenges, HEI plans and strategies should consider all the non-technical challenges related to stakeholders' attitudes, including all cognitive, behavioral, and affective challenges to assure the successful adoption of DT in HEIs.

In the future, the scope of this research may be expanded by incorporating challenges of other stakeholders' attitudes, such as administrators, employees, and managers into the investigated challenges of instructors and students. Further, studying the causation and relationship between the challenges of cognitive, behavior, and affective challenges and other categories of challenges can enhance the decisionmaking process. Testing the model with a larger pool of instructors and students can enhance the accuracy of ranking the challenges of stakeholders' attitudes. An important area of interest is to provide Saudi universities with the current situation of priority of challenges. The importance comes from the current state of Saudi universities, where many of them are recently established and currently working on the process of designing and adopting DT plans and strategies.

Finally, even though the suitability of adopting the ANP method in this research, an important area of interest can be testing the proposed model with other MCDM methods and comparing results. Recent MCDM methods have been developed 
during the past decades, such as the Best-Worst Method (BWM), where they have some advantages over the ANP that can enhance the decision-making process. Some of the advantages include time to evaluate participants' evaluations, the complexity of adopting the method, and the number of comparisons that the participant needs to provide. When testing the proposed model using different MCDM methods, decision-makers at HEIs can adopt this model and conduct their analyses by using the most suitable MCDM method.

\section{References}

Al-Ohali, Y., Alhojailan, M., Palavitsinis, N., Najjar, J., Koutoumanos, A., \& AlSuhaibani, A. (2019). Human factors in digital transformation of education: Lessons learned from the future gate at Saudi K-12. In International Conference on Applied Human Factors and Ergonomics (pp. 52-64). Springer.

Al-Rahmi, W. M., Alias, N., Othman, M. S., Marin, V. I., \& Tur, G. (2018). A model of factorsaffecting learning performance through the use of social media in Malaysian higher education. Computers \& Education, 121, 59-72.

Bharadwaj, A. S. (2000). A resource-based perspective on information technology capability and firm performance: An empirical investigation. MIS Quarterly, 24(1), 169-196.

Bharadwaj, A., El Sawy, O. A., Pavlou, P. A., \& Venkatraman, N. (2013). Digital business strategy: Toward a next generation of insights. MIS Quarterly, 37(2), 471-482.

Blasco-Arcas, L., Buil, I., Hernández-Ortega, B., \& Sese, F. J. (2013). Using clickers in class. The role of interactivity, active collaborative learning and engagement in learning performance. Computers \& Education, 62, 102-110.

Bozanta, A., \& Mardikyan, S. (2017). The effects of social media use on collaborative learning: A case of Turkey. Turkish Online Journal of Distance Education, 18(1), 96-110.

Cassidy, K. J., Sullivan, M. N., \& Radnor, Z. J. (2019). Using insights from (public) services management to improve student engagement in higher education. Studies in Higher Education, 1-17. https://doi. org/10.1080/03075 079.2019.1665010.

Durão, N., Ferreira, M. J., Pereira, C. S., \& Moreira, F. (2019). Current and future state of Portuguese organizations towards digital transformation. Procedia Computer Science, 164, 25-32.

Erbay, H., \& Yıldırım, N. (2018). Technology selection for digital transformation: A mixed decision making model of AHP and QFD. In The International Symposium for Production Research (pp. 480-493). Springer.

Filkins, B. L., Kim, J. Y., Roberts, B., Armstrong, W., Miller, M. A., Hultner, M. L., Castillo, A. P., Ducom, J. C., Topol, E. J., \& Steinhubl, S. R. (2016). Privacy and security in the era of digital health: What should translational researchers know and do about it? American Journal of Translational Research, 8(3), 1560.

Fitzgerald, M., Kruschwitz, N., Bonnet, D., \& Welch, M. (2014). Embracing digital technology: A new strategic imperative. MIT Sloan Management Review, 55(2), 1.

Fonseca, D., Martí, N., Redondo, E., Navarro, I., \& Sánchez, A. (2014). Relationship between student profile, tool use, participation, and academic performance with the use of augmented reality technology for visualized architecture models. Computers in Human Behavior, 31, 434-445.

Fredricks, J. A., Blumenfeld, P. C., \& Paris, A. H. (2004). School engagement: Potential of the concept, state of the evidence. Review of Educational Research, 74(1), 59-109.

Heavin, C., \& Power, D. J. (2018). Challenges for digital transformation-towards a conceptual decision support guide for managers. Journal of Decision Systems, 27(sup1), 38-45.

Henrie, C. R., Halverson, L. R., \& Graham, C. R. (2015). Measuring student engagement in technologymediated learning: A review. Computers \& Education, 90, 36-53.

Joseph, J. (2012). The barriers of using education technology for optimizing the educational experience of learners. Procedia-Social and Behavioral Sciences, 64, 427-436.

Limani, Y., Hajrizi, E., Stapleton, L., \& Retkoceri, M. (2019). Digital transformation readiness in higher education institutions (HEI): The case of Kosovo. IFAC-PapersOnLine, 52(25), 52-57. 
Newman, D. (2017). Top 10 trends for digital transformation in 2018, forbes CMO network.

Panetta, K. (2016). Analyst answers: The CIO's biggest digital transformation challenges. Retrieved January, 24, p. 2018.

Pérez-López, R., Gurrea-Sarasa, R., Herrando, C., Martín-De Hoyos, M. J., Bordonaba-Juste, V., \& Utrillas-Acerete, A. (2020). The generation of student engagement as a cognition-affect-behaviour process in a twitter learning experience. Australasian Journal of Educational Technology, 36(3), $132-146$.

Rashid, T., \& Asghar, H. M. (2016). Technology use, self-directed learning, student engagement and academic performance: Examining the interrelations. Computers in Human Behavior, 63, 604-612.

Rasiah, R. R. V. (2014). Transformative higher education teaching and learning: Using social media in a team-based learning environment. Procedia-Social and Behavioral Sciences, 123, 369-379.

Reis, J., Amorim, M., Melão, N., \& Matos, P. (2018). Digital transformation: A literature review and guidelines for future research. In World conference on information systems and technologies (pp. 411-421). Springer.

Saaty, R.W. (2003). Decision making in complex environments. Super Decisions.

Saaty, T. L. (1990). How to make a decision: The analytic hierarchy process. European Journal of Operational Research, 48(1), 9-26.

Saudi Vision 2030 (2018). National transformation program. Retrieved from https://vision2030.gov.sa/en/ programs/NTP. Accessed 15 Aug 2020.

Solis, B., Li, C., \& Szymanski, J. (2014). The 2014 state of digital transformation. Altimeter Group, 1(1), $1-33$.

Stolterman, E., \& Fors, A.C. (2004). Information technology and the good life. In Information systems research (pp. 687-692). Springer.

Taslicali, A. K., \& Ercan, S. (2006). The analytic hierarchy and the analytic network processes in multicriteria decision making: A comparative study. Journal of Aeronautics and Space technologies, 2(4), 55-65.

Tiersky, H. (2017). 5 top challenges to digital transformation in the enterprise. CIO, 1-6. Retrieved from https://www.cio.com/article/3179607/5-top-challenges-to-digital-transformation-in-the-enterprise. html. Accessed 10 Aug 2020.

Trowler, V. (2010). Student engagement literature review. The Higher Education Academy, 11(1), 1-15.

Westerman, G., Calméjane, C., Bonnet, D., Ferraris, P., \& McAfee, A. (2011). Digital Transformation: A roadmap for billion-dollar organizations. MIT Center for Digital Business and Capgemini Consulting, 1, 1-68.

Yucel, S. (2018, December). Estimating the benefits, drawbacks and risk of digital transformation strategy. In 2018 International Conference on Computational Science and Computational Intelligence (CSCI) (pp. 233-238). IEEE.

Publisher's note Springer Nature remains neutral with regard to jurisdictional claims in published maps and institutional affiliations. 